\title{
THE INTERACTION OF FLOODS WITH TRANSPORT INFRASTRUCTURE
}

\author{
IVAN VANÍČEK ${ }^{a, *}$, JIŘí VANÍČEK ${ }^{b}$ \\ ${ }^{a}$ Czech Technical University in Prague, Faculty of Civil Engineering, Department of Geotechnics, Thákurova 7, \\ 16629 Prague, Czech Republic \\ ${ }^{b}$ Geosyntetika Ltd., Nikoly Tesly 3, 16000 Prague, Czech Republic \\ * corresponding author: ivan.vanicek@cvut.cz
}

ABstract. Current demands on transport infrastructure are very often associated with the terms of "sustainability, availability and affordability". The first term directly refers to the basic principles of sustainable construction in transport infrastructure, primarily motorway and railways, and how they are related to a very significant consumption of land, energy and natural aggregates. This paper is focused on the other two terms, availability and affordability. These principles are intended to guarantee proper functioning of communication even in nonstandard situations such as natural hazards, most typically floods. To avoid a total collapse of transport infrastructure, the term robustness is often applied, recognizing that this term is not a substitute for another outcome - namely a more expensive structure. The paper shows the possibilities for elimination of the negative impact of floods on transport infrastructure as they relate to different types of interaction and different types of floods.

KEYWORDS: Flood protection, transport infrastructure, dams.

\section{DifFERENT TYPES OF FLOODS AND A BASIC CASE OF INTERACTION}

In principle three types of floods are differentiated:

- Flash floods, caused by extreme rainfall on a relatively small river basin. Here, prognosis is very difficult.

- Spring floods - situated at the foot of mountains, where floods are caused by the synergy of snow melting with heavy rainfall. Prognosis with respect to place and time is much better here and countermeasures can be given a long term character.

- Regional floods, affecting a large area involving more river basins, and having duration of a few days up to several weeks. Prognosis is average here, based on climate and especially rainfall forecasting.

With respect to the relatively small area affected by flash floods, the interaction with transport infrastructure is focused on two basic examples:

- Erosion of the communication route running parallel with a river stream.

- The threat to bridges crossing this river stream.

Dam systems, which in the Czech Republic are more than a century old, are the main countermeasures against spring floods. The dam system in Jizera Mountains, or rather at the foot of these mountains, is such an example. When the capacity of these dam reservoirs is not sufficient, then the interaction has a similar character as for the previous case.

Floods in 1997 and 2002 can be seen as classical examples of large regional floods. During the floods in
2002 , there were two peaks in intensity of rainfall very close to each other, separated by roughly 2 or 3 days only. After the first peak, the land was saturated and therefore nearly all precipitation was running directly to the water course. In this case historical small dams on the small rivers and new large dams and the main water courses (as in the Vltava river cascade) acted as the main engineered structures in order to retain and flatten the flood wave. Therefore to the previously mentioned interactions, we can add overflowing with the potential failure of small historical dams as their dam crest is often used as a transport corridor. Overflowing with potential failure of dikes along a river is another important case of interaction, as it can cause flooding of a wider developed area also containing transport infrastructure.

With respect to transport infrastructure, the focus here is on motorways and railways and not on other possibilities such as airports or parking space. Flooding of the Prague Metro during the floods in 2002 would really deserve specific attention [1].

The basic case of interaction studied here is the flooding of transport infrastructure, where the water is above its level and a structure is thus rendered unusable. Nevertheless, often the damage is relatively small and the transport infrastructure can be used shortly after flood wave cessation. The bridge over the river Labe, flooded on August 15 and reopened on August 20, 2002, would be a good example, see Figure 1 .

In other cases the interaction can lead to part or complete failure of the structure of transport lines. The different types of failure are discussed in the next chapter together with practical examples. Classifica- 

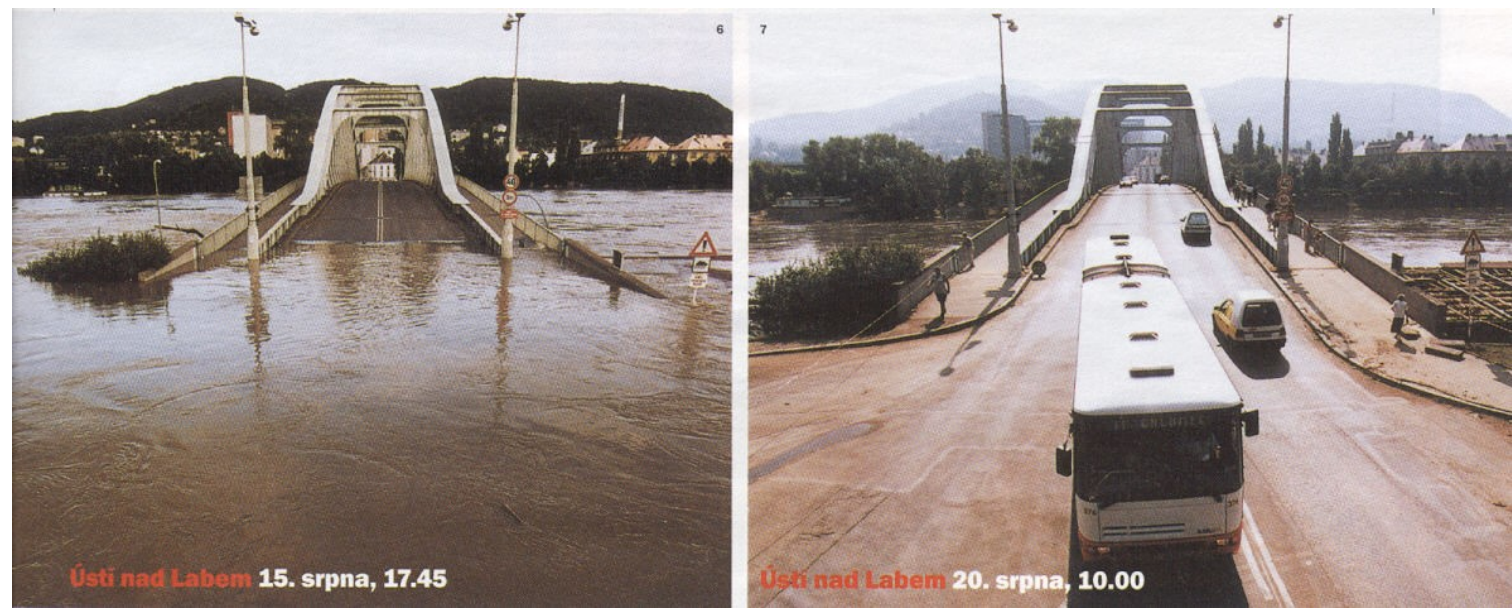

FiguRE 1. Re-opening of the bridge in Ústí nad Labem five days after flooding.

tion of these failures is consistent with the Eurocode 7 - EN 1997 Geotechnical design.

\section{THE CHARACTER OF TRANSPORT INFRASTRUCTURE FAILURES}

Practical knowledge based on particular cases shows that failure of the earth structures in transport network systems is very often connected with a limit state of failure of the type HYD, that is with erosion. This erosion can be either surface or internal. Surface erosion is typical for crest overflow or as the result of flowing water contact with an upstream slope. A typical case of slope instability was in practice not actually observed and such a failure would deserve a more demanding explanation.

\subsection{Floods in the Blatná Region in 2002}

The specificity of floods in the Blatná region was due to the combination of heavy rainfall with additional waves from failed dams. Seven small dams were affected on the small river of Lomnice, of which five failed completely. For this small river basin the authors specified a so called domino effect of failures. At the beginning of this basin, there is situated the most significant dam (the highest with a larger reservoir volume) and if it fails, then the others situated below have a limited chance to survive [2]4]. Failure by surface erosion prevails, but at least two failures can be attributed to internal erosion where seeping water, due to a high hydraulic gradient, used the most disposed path along which internal erosion started.

For the Lomnice river basin, there was a chance to compare the floods which occurred in 1895 with those in 2002. Although for the first case the crest overflow was smaller, all 7 dams failed. In 2002 two dams did not fail completely, namely the dams the crests of which were covered by an asphalt carpet. Figure 2 shows one such example.

Another example of the interaction was observed on this river basin. The river Lomnice crosses the railway track Blatná - Nepomuk. The relatively large culvert was not able to transfer the supplemental flood wave from the above situated failed dam. This was probably also due to a partially blocked flow profile caused by transported vegetation, by shrub and smaller trees. A subsequent overflowing onto the track started and the erosion left the rails on the track raised above the ground, as shown in Figure 3.

Numerical modelling of the flood wave is very important for the basin where a domino effect can be expected. This brings an estimation of its peak when arriving below the situated dam. This modelling should include also the potential interaction with transport infrastructure. In some safer cases, this interaction can play a positive role. Delay and decrease of the flood wave passing through the culvert can have this positive impact when reaching below the situated reservoir and dam crest [5].

\subsection{FLOODS IN THE FRÝDLANT REGION IN 2010}

Significant rainfall in the northwest part of Jizera Mountains brings a very quick rise to flood wave on the small rivers Smědá and Řasnice which flow through the town of Frýdlant. Most of the town was flooded on Saturday August $7^{\text {th }}$, 2010. The roads changed into rivers. Regrettably some people died. Damage to properties, on transport lines and on infrastructures was very high. Figure 4 shows the example where a parallel communication line was partly eroded by water stream in interaction during floods.

A brief note can be added on the process of reconstruction of a damaged transport infrastructure similar to the above mentioned case. In the frame of an intention to repair the transport line as soon as possible, the reconstruction was solved under extra-ordinary conditions without a deeper discussion and preparation about the most appropriate solution. Therefore there is some possibility that with the next floods the transport infrastructure will fail in the same place.

However, this type of lateral interaction - erosion also can be connected with slope instability, which can 


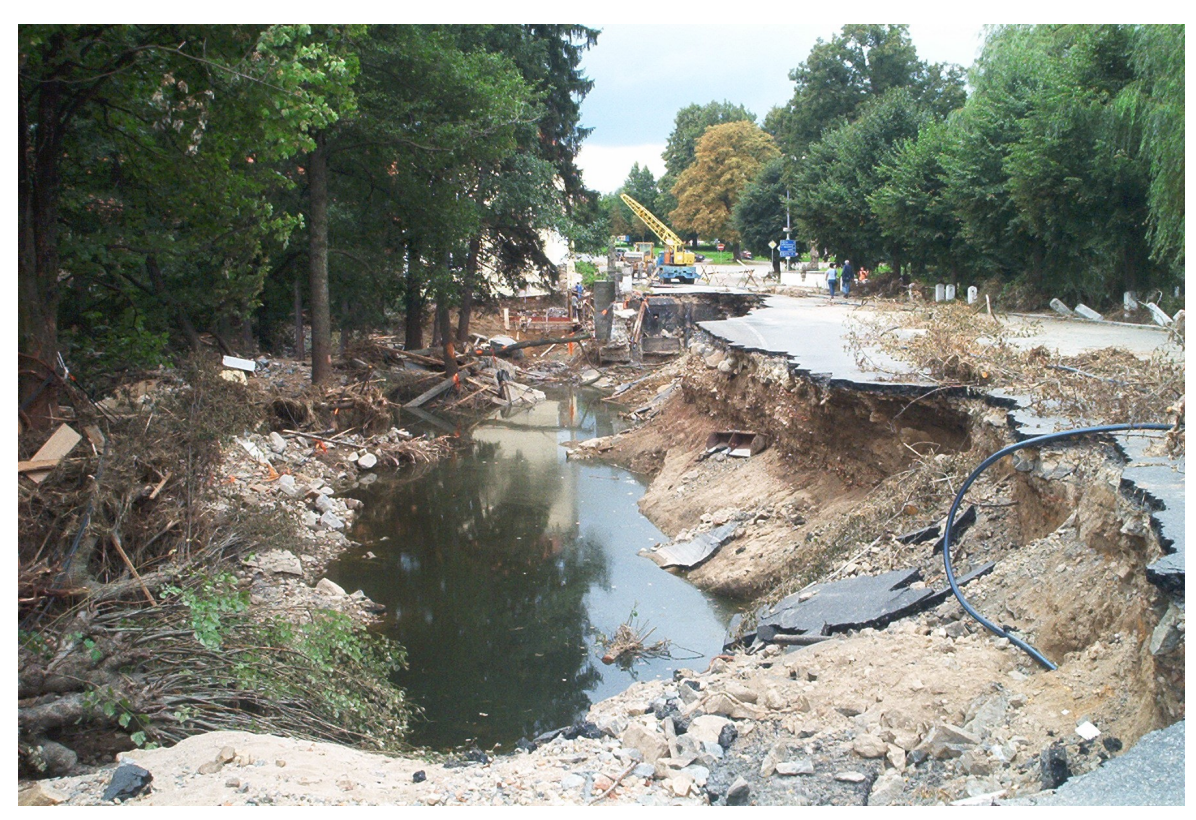

Figure 2. Example of disturbance of the downstream slope and crest of a dam which is used as an important communication line - E 49.

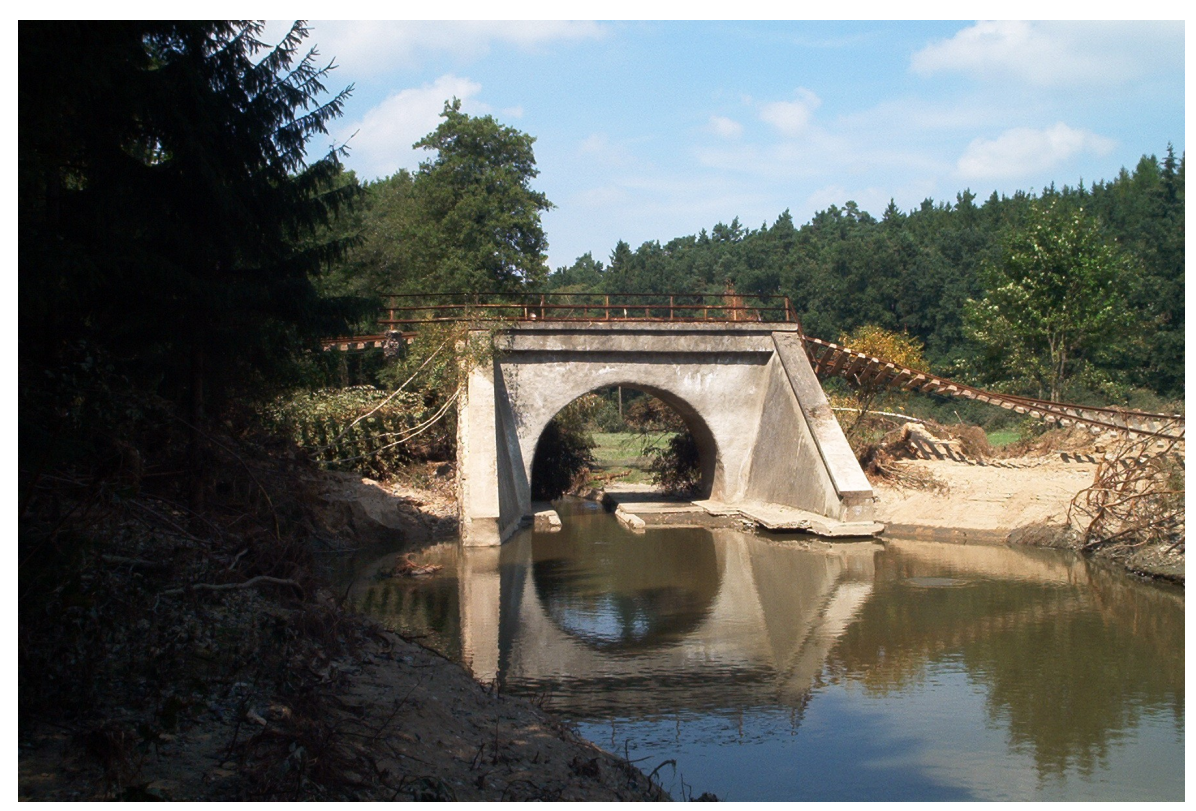

Figure 3. The erosion of Blatná - Nepomuk railway embankment. The water table shown on photo is typical for an ordinary flow rate. 


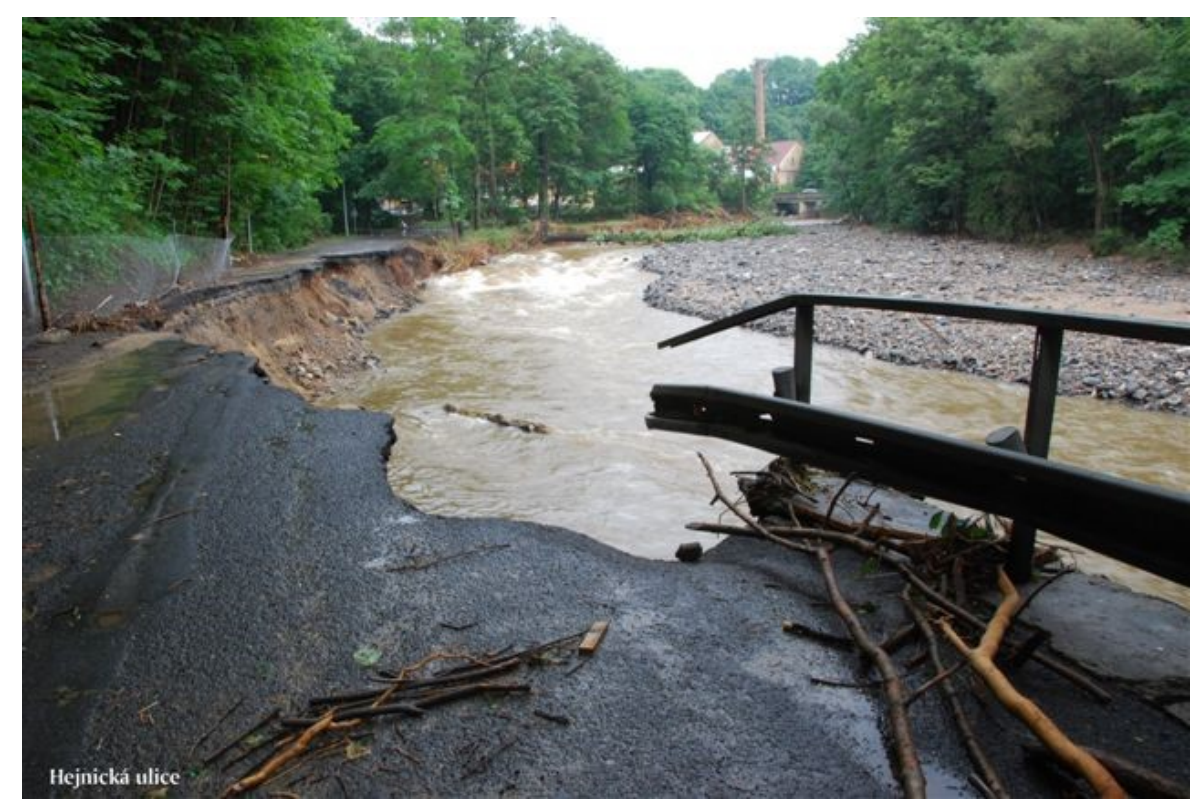

FiguRE 4. An example of lateral erosion of a transport embankment in the Frýdlant region, 2010.

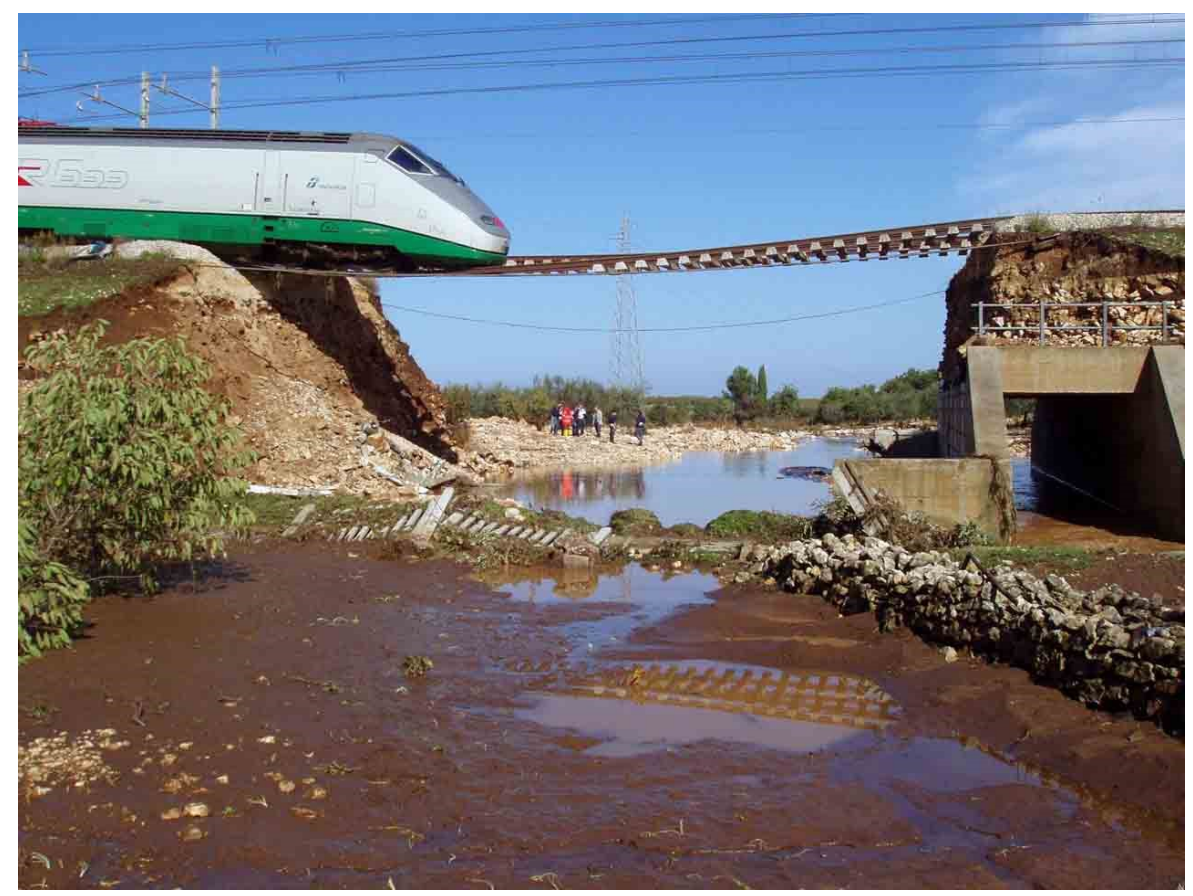

Figure 5. Failure of the railway track Bari - Taranto, 2005. 
be simulated later on. Failures in similar cases always represent a limit situation, a limit state of failure, on which present-day codes are fixed. Regrettably the back analysis is not performed immediately as no team of experts is present or sent. Eventually, in most cases it is difficult to specify the extreme loading, or maximal water level, during which failure occurred.

\subsection{Floods in the BARI REGION IN 2005, ITALY}

The problem of floods and their interaction with transport infrastructure was the main concern of the study by the post-graduate student M.Burdo [6]. During heavy rainfall the surface runoff was greater than the capacity of the culvert below the railway track Bari - Taranto. The embankment was damaged, and only due to a rather positive coincidence the problem had no exceptional impact as the train stopped just in front of the damaged part of the embankment, see Figure 5 . Therefore the major part of this post graduate study was connected with analytical and numerical methods of investigating slope stability, and later on with a combination of more individual aspects. The infiltration of retained water into the partially saturated embankment was simulated, and then the subsequent impact on slope instability was checked. After this the rainfall on the "downstream slope" was also simulated. Air bubbles were enclosed between saturated zones, and with continuing infiltration, the pressure in the air bubbles went up and this can cause the uplift of the saturated downstream slope. Therefore the subsequent collapse can be associated both with internal erosion and with slope instability.

The credibility of such a scenario was subject to a simple modelling in the laboratory. Dry sand was deposited in a vertical glass tube and covered on top by a saturated layer. A vertical tube was submerged into a vessel with water. This water, due to capillary force, went up and closed the air bubbles between the saturated zones. The air pressure went up to the limit state when the saturated zone at the top was separated, and lifted up. This simple model proved that this scenario was plausible and it can explain many spread shallow landslides which occur in partially saturated soils during heavy rainfall.

\section{Conclusions}

The interaction of floods with transport infrastructure has a very significant impact on functionality of the system. In most cases this impact is in a negative direction. The presented examples point to the limit states of failure of an earth structure during extreme loading and through this show how to proceed in the future. For a current state this means selecting the most critical places and subsequently supervising their reinforcement, or in cases of reparation of failed parts by selecting the most appropriate methods, preferably in advance. At the same time it is appropriate to distinguish the earth structures which are in contact with water in the long term as in historical small dams the crest of which are used as transport line, and which possibly are in contact with water only in an exceptional case. The last case represented by motorway or railway embankments and by dykes, need some special attention as soils are unsaturated during first contact with flood wave.

\section{REFERENCES}

[1] K. Soga, I. Vaníček, A. Gens. Micro-Measurement and Monitoring System for Ageing Underground Infrastructure. CTU Press, Prague, 2011.

[2] I. Vaníček. Embankments of small water reservoirs and dykes, Keynote Lecture, Czech ICOLD Dam Days, České Budějovice, 2004.

[3] I. Vaníček, J. Vaníček. Rehabilitation of old earth dams failed during heavy floods in 2002. In Proceedings of the conference on New development in Dam Engineering. A. A. Balkema Publishers, London, 2004.

[4] I. Vaníček, M. Vaníček. Earth Structures in Transport, Water and Environmental Engineering. Springer, Netherlands, 2008. DOI:10.1007/978-1-4020-3964-5

[5] I. Vaníček, J. Vaníček, T. Pecival. Risk evaluation of a domino effect of dam failure on small river-basins. In Proceedings of the European conference on Flood Risk Management. E3S Web of Conferences, Lyon, 2016. DOI:10.1051/e3sconf/20160707009.

[6] M. Burdo. Final report of the postgraduate traineeships, 2016. 